\title{
Hearing and Kidney: Effects of Chronic Kidney Disease on Various Auditory Parameters - Results from a Tertiary Care Hospital in India
}

\author{
Deepak Jain, ${ }^{1}$ H. K. Aggarwal, ${ }^{2}$ Shailesh Bhatia, ${ }^{3}$ Jaikrit Bhutani ${ }^{3}$
}

\begin{abstract}
:
Background:An association between chronic kidney disease (CKD) and hearing loss was first described in patients with Alport syndrome. Patients with CKD develop sensorineural hearing loss with the progression of the disease. Studies using BAER as an index of auditory function among patients with CKD showed evidence of various degrees of auditory dysfunction.
\end{abstract}

Materials and methods: 100 adult CKD patients (stage $3-5$ and 5D) and 50 controls were included in the study. Clinical and biochemical parameters were assessed and all the patients and controls underwent Pure Tone Audiometry (PTA) and Brainstem Auditory Evoked Response (BAER) evaluation.

Results: When hearing thresholds were compared between the patients and controls PTA showed an increase in hearing threshold in all patient groups. This increase was more noticeable at higher frequencies (4 and $8 \mathrm{kHz}$ ). Compared with healthy controls, a highly significant delay was observed in CKD patients in both absolute and interpeak latencies in BAER in the present study.

Conclusion: The present study provides a concrete evidence to the otherwise disputed relation of auditory function in CKD proving that hearing is permanently affected by ESRD at all levels of the auditory neural pathway.

Key Words: chronic kidney disease, sensorineural hearing loss, Pure Tone Audiometry, Brainstem Auditory Evoked Response.

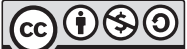

DOI: https://doi.org/l0.3329/jom.v2lil.44098

Copyright: (C) 2020 Jain M et al. This is an open access article published under the Creative Commons Attribution-NonCommercial-NoDerivatives 4.0 International License, which permits use, distribution and reproduction in any medium, provided the original work is properly cited, is not changed in any way and it is not used for commercial purposes.

Received: 19 June, 2019;

Accepted: 09 August, 2019

\section{Introduction:}

Contrary to common belief the incidence and prevalence of hearing loss, both subclinical and overt, is high in patients with Chronic Kidney Disease (CKD). Patients with CKD develop sensorineural hearing loss with the progression of the disease. The etiology for this hearing loss is not well defined although the pathophysiologic and biochemical

1. Associate Professor, Department of Medicine and Division of Nephrology, Pt. B.D. Sharma University of Health Sciences, Rohtak (Haryana), India

2. Senior Professor \& Head Department of Medicine III and Division of Nephrology, Pt. B.D. Sharma University of Health Sciences, Rohtak (Haryana), India

3. Resident, Department of Medicine Pt. B.D. Sharma University of Health Sciences, Rohtak (Haryana), India

Corresponding author: Dr. Deepak Jain, Associate Professor, Department of Medicine, Pt. B.D. Sharma University of Health Sciences, Rohtak-124001 (Haryana), India. Email: jaindeepakdr @gmail.com, Ph: +91-9416147887. changes associated with $\mathrm{CKD}$ are believed to cause auditory pathway damage, both at the sensory organ and neuronal levels. Ototoxic drugs, diabetes, infection, noise exposure and congenital otonephropathies are the known etiologic factors that account for the majority of hearing losses occurring in CKD, with the most common being ototoxic diuretics and antibiotics.

Cochlear dysfunction in kidney disease was first established as "Hereditary Familial Congenital Hemorrhagic Nephritis". This syndrome is characterised by nephropathy, bilateral symmetric sensorineural hearing loss, ocular abnormalities and hereditary origin. The association of hereditary nephritis and deafness was established by examination of hearing with controlled audiometry and the structural abnormalities between glomerulus and stria vascularis showed that both the kidney and cochlea were concerned with electrolyte transport. ${ }^{2,3}$ Changes in the outer hair cells and spiral ganglia do occur in CKD as witnessed in different temporal bone 
sections and audiovestibular changes result from the water and electrolyte imbalance accompanying $\mathrm{CKD} .{ }^{4}$ The function of both the kidney and the cochlea includes complex processes of water and ion regulation which are dependent on the functioning of different proton pump systems which maintain homeostasis of $\mathrm{pH}$ and ions. 5,6

The Brainstem Auditory Evoked Response is an early evoked response that reflects neural function along the ascending auditory pathway, from the cochlea to the inferior colliculus. Studies using BAER as an index of auditory function among patients with CKD showed evidence of various degrees of auditory dysfunction.

The present study is done to explore the potential usefulness of electrophysiologic indices for evaluating the physical status of patients being treated for end stage CKD. These indices can be helpful in early diagnosis and management of CNS dysfunction, cognitive impairment, and sensorineural hearing loss in patients of chronic kidney disease.

\section{Material and methods:}

This prospective observational study was conducted on 100 adult patients of CKD and 50 healthy controls on regular follow up of Kidney and Dialysis Clinic at Pandit Bhagwat Dayal Sharma Post Graduate Institute of Medical Sciences, Rohtak. This study was duly approved by the Ethical committee and the Post graduate board of studies of the institution. The inclusion criteria of the CKD patients were age between 18 and 75 years, CKD stage 3, 4 and 5, and patients on maintenance hemodialysis for at least 3 months. Patients excluded were those who had congenital hearing loss or middle ear alterations, history of excessive exposure to noise, history of use of ototoxic medications, patients using any type of hearing aids, and post renal transplant patients.

The study participants were divided into two groups:

Group I consisted of 100 patients of CKD (stage 3 to 5D).

Group II consisted of 50 healthy controls.

Group I was further subdivided into 4 groups A, B, C and D based on CKD staging by NKF-K/DOQI. ${ }^{7}$

Group A consisted of 25 patients with eGFR between 30-59 $\mathrm{ml} / \mathrm{min} / 1.73 \mathrm{~m}^{2}$ (CKD Stage 3).

Group B consisted of 25 patients with eGFR between 15-29 $\mathrm{ml} / \mathrm{min} / 1.73 \mathrm{~m}^{2}$ (CKD Stage 4).

Group C consisted of 25 patients with of eGFR $<15 \mathrm{ml} / \mathrm{min} /$ $1.73 \mathrm{~m}^{2}$, not on hemodialysis (CKD stage 5 ).

Group D consisted of 25 patients with of eGFR $<15 \mathrm{ml} / \mathrm{min} /$ $1.73 \mathrm{~m}^{2}$ on hemodialysis (CKD stage-5 D).
After accounting for the inclusion and exclusion criteria patients and controls included in the study underwent a battery of investigations which included a complete blood count, blood urea, serum creatinine, blood sugar, serum calcium and phosphorus, serum uric acid, seum albumin, serum electrolytes, urine routine examination, 24 hour urine for proteinuria, viral markers (HIV/HBsAg/Anti HCV), ECG, Chest X-ray PA view, and ultrasound abdomen for bilateral kidney size and echotexture. All the patients and controls underwent Pure Tone Audiometry (PTA) and Brainstem Audiometry Evoked Response.

At the end of the study, the data was expressed as mean $\pm 1 \mathrm{SD}$ or range. Probability values $<0.05$ were considered to be significant in all the analyses. Independent t-test and ANOVA test were used to analyze differences in quantitative variables between the groups. The correlations were tested using Pearson correlation coefficient analysis. All statistical calculations were carried out using SPSS 21.0 software.

\section{Results:}

The mean age of group I and II was 53 years and 46 years respectively. Out of the 100 patients 64 were male and 36 were female while out of the 50 controls 26 were male and 24 were female. The comparison of mean hearing threshold between group I and group II is shown in table 1a with the difference being statistically significant $(\mathrm{p}<0.0001)$. This shows that patients with CKD have sensorineural hearing loss which is grater at higher frequencies. However on further subgroup analysis (table $1 \mathrm{~b}$ ) there was no significant difference among any of the subgroups. Hearing loss, defined as hearing threshold greater than $25 \mathrm{~dB}$, was found in 19 out of 25 patients each (76\%) in group A and B, 20 out of 25 patients $(80 \%)$ in group $\mathrm{C}$ and 17 out of 25 patients $(68 \%)$ in group D. Comparing between the dialysed and nondialysed group of stage $-\mathrm{V}$ patients shows significant difference at all frequencies except 2 and $4 \mathrm{kHz}$ with the dialysed patients having more severe hearing loss.

The BAER latencies for group I and II are given in table IIa with all the differences being statistically significant between the two groups $(p<0.0001)$. The latencies for the subgroups A, B, C, and D are given in table IIb. The difference among the subgroups was statistically significant for waves I and III, and interpeak III-V latency $(\mathrm{p}<0.05)$. In addition the difference between the non-dialysed and the dialysed groups was significant only for wave I, and interpeak latencies III-V and I-V. Comparing between the dialysed and non-dialysed group of stage- $\mathrm{V}$ patients show significant difference at all frequencies except 2 and $4 \mathrm{kHz}$ with the dialysed patients having more severe hearing loss. Similar comparison for the BAER latencies showed significant difference only for wave $\mathrm{I}$, and interpeak latencies III-V and I-V. 
Table Ia: Comparison of hearing threshold of cases vis-à-vis controls

\begin{tabular}{lccc}
\hline Pure Tone Audiometry & $\begin{array}{c}\text { Group I }(\mathrm{N}=100) \\
\text { Mean } \pm \text { S.D }\end{array}$ & $\begin{array}{c}\text { Group II }(\mathrm{N}=50) \\
\text { Mean } \pm \text { S.D }\end{array}$ & P Value* \\
\hline $0.25 \mathrm{kHz}$ & $11.59 \pm 3.24$ & $8.54 \pm 2.28$ & $<.0001$ \\
$0.5 \mathrm{kHz}$ & $12.59 \pm 3.24$ & $8 \pm 1.95$ & $<.0001$ \\
$1.0 \mathrm{kHz}$ & $13.56 \pm 3.37$ & $7.58 \pm 2.29$ & $<.0001$ \\
$2.0 \mathrm{kHz}$ & $14.98 \pm 3.41$ & $7.02 \pm 2$ & $<.0001$ \\
$4.0 \mathrm{kHz}$ & $19.33 \pm 4.55$ & $8.6 \pm 2.33$ & $<.0001$ \\
$8.0 \mathrm{kHz}$ & $28.96 \pm 5.97$ & $10.82 \pm 2.37$ & $<.0001$ \\
\hline
\end{tabular}

*Analyzed by Independent t-test

Table Ib: Comparison of hearing threshold in different groups of CKD patients

\begin{tabular}{lccccc}
\hline Pure Tone Audiometry & $\begin{array}{c}\text { Group } \mathrm{A}(\mathrm{N}=25) \\
\text { Mean } \pm \text { S.D }\end{array}$ & $\begin{array}{c}\text { Group B }(\mathrm{N}=25) \\
\text { Mean } \pm \text { S.D }\end{array}$ & $\begin{array}{c}\text { Group C }(\mathrm{N}=25) \\
\text { Mean } \pm \text { S.D }\end{array}$ & $\begin{array}{c}\text { Group D }(\mathrm{N}=25) \\
\text { Mean } \pm \text { S.D }\end{array}$ & $\begin{array}{c}\mathrm{P} \\
\text { value* }\end{array}$ \\
\hline $0.25 \mathrm{kHz}$ & $12.12 \pm 3.14$ & $11.92 \pm 3.35$ & $12.24 \pm 3.11$ & $10.08 \pm 3.07$ & 0.059 \\
$0.5 \mathrm{kHz}$ & $13.12 \pm 3.14$ & $12.92 \pm 3.35$ & $13.24 \pm 3.11$ & $11.08 \pm 3.07$ & 0.059 \\
$1.0 \mathrm{kHz}$ & $14.12 \pm 3.14$ & $13.92 \pm 3.35$ & $14.24 \pm 3.11$ & $11.96 \pm 3.52$ & 0.051 \\
$2.0 \mathrm{kHz}$ & $15.12 \pm 3.14$ & $14.92 \pm 3.35$ & $15.24 \pm 3.11$ & $14.64 \pm 4.12$ & 0.933 \\
$4.0 \mathrm{kHz}$ & $19.08 \pm 4.04$ & $18.8 \pm 4.27$ & $19.28 \pm 4.03$ & $20.16 \pm 5.8$ & 0.840 \\
$8.0 \mathrm{kHz}$ & $29.96 \pm 4.97$ & $29.68 \pm 5.23$ & $30.32 \pm 4.98$ & $25.88 \pm 7.55$ & 0.218 \\
\hline
\end{tabular}

*Analyzed by ANOVA

Table IIa: Comparison of Brainstem Evoked Response Audiometry latencies (absolute and interpeak) of cases vis-à-vis controls

\begin{tabular}{lccc}
\hline $\begin{array}{l}\text { Brainstem Evoked Response } \\
\text { Audiometry }\end{array}$ & $\begin{array}{c}\text { Group I }(\mathrm{N}=100) \\
\text { Mean } \pm \text { S.D }\end{array}$ & Group II (N=50) & Pean \pm S.D \\
\hline I & $1.82 \pm 0.11$ & $1.73 \pm 0.07$ & $<.0001$ \\
III & $4.02 \pm 0.13$ & $3.8 \pm 0.11$ & $<.0001$ \\
V & $5.81 \pm 0.16$ & $5.53 \pm 0.09$ & $<.0001$ \\
I-III & $2.2 \pm 0.1$ & $2.07 \pm 0.07$ & $<.0001$ \\
III-V & $1.8 \pm 0.12$ & $1.73 \pm 0.07$ & $<.0001$ \\
I-V & $4 \pm 0.15$ & $3.8 \pm 0.07$ & $<.0001$ \\
\hline
\end{tabular}

*Analyzed by Independent t-test

Table IIb: Comparison of Brainstem Evoked Response Audiometry latencies (absolute and interpeak) among different groups of CKD patients

\begin{tabular}{lccccc}
\hline $\begin{array}{l}\text { Brainstem Evoked } \\
\text { Response Audiometry }\end{array}$ & $\begin{array}{c}\text { Group A(N=25) } \\
\text { Mean } \pm \text { S.D }\end{array}$ & $\begin{array}{c}\text { Group B(N=25) } \\
\text { Mean } \pm \text { S.D }\end{array}$ & $\begin{array}{c}\text { Group C(N=25) } \\
\text { Mean } \pm \text { S.D }\end{array}$ & $\begin{array}{c}\text { Group D (N=25) } \\
\text { Mean } \pm \text { S.D }\end{array}$ & P value* \\
\hline I & $1.79 \pm 0.12$ & $1.81 \pm 0.12$ & $1.81 \pm 0.1$ & $1.87 \pm 0.07$ & 0.037 \\
III & $3.98 \pm 0.12$ & $3.99 \pm 0.12$ & $4.03 \pm 0.13$ & $4.09 \pm 0.11$ & 0.005 \\
V & $5.82 \pm 0.16$ & $5.78 \pm 0.2$ & $5.83 \pm 0.14$ & $5.8 \pm 0.14$ & 0.656 \\
I-III & $2.19 \pm 0.11$ & $2.18 \pm 0.11$ & $2.22 \pm 0.11$ & $2.22 \pm 0.09$ & 0.437 \\
III-V & $1.85 \pm 0.13$ & $1.83 \pm 0.12$ & $1.81 \pm 0.12$ & $1.71 \pm 0.07$ & 0.0003 \\
I-V & $4.04 \pm 0.16$ & $4.01 \pm 0.14$ & $4.02 \pm 0.13$ & $3.93 \pm 0.13$ & 0.065 \\
\hline
\end{tabular}

*Analyzed by ANOVA 


\section{Discussion:}

An association between chronic kidney disease and hearing loss was first described in patients with Alport syndrome. ${ }^{1}$ However, anatomical, physiological, pathological, and pharmacological similarities between the nephron and stria vascularis of the cochlea may explain this association in cases that are not related to syndromes or genetic diseases. ${ }^{8}$ There is physiologic, ultrastructural and antigenic analogies between the kidney and the cochlea which permit to infer that the link between inner ear damage and kidney failure is likely to be much more than a coincidental finding. ${ }^{9}$ The similarities of labyrinthine and renal function are well exemplified by the shared essential importance of aquaporins, specific cellular water channels, and by the presence of an ion transport system that to date has been demonstrated only in the rat and in the human endolymphatic sac beside the kidney. Furthermore it has been shown that there is an immunological connection between the kidney and inner ear in that antibodies raised against the nephron also deposit in the stria vascularis. ${ }^{10}$ Sensorineural hearing loss at high frequencies is the most common type in patients with chronic kidney disease, and includes both cochlear impairment and lesions to particular portions of the auditory pathway. ${ }^{11}$

When hearing thresholds were compared between the patients and controls PTA showed an increase in hearing threshold in all patient groups. The hearing loss was bilaterally symmetrical, involving all frequencies, particularly the higher ones. The results of the present were similar to those of Bains et al. who showed a definite deterioration of audiologic functions among CKD patients. In that study the incidence of sensorineural hearing loss among the nondialysed group of CKD patients was $70 \%$ while in the dialysed group it was $60 \%{ }^{12}$ Bazzi et al. found an incidence of $77 \%$ including patients with mild and very mild hearing loss. Similar to the findings of the present study hearing loss in this study also occurred mainly in the high frequency band (4 and $8 \mathrm{kHz}$ ). The observation of hearing loss found to be more at higher frequencies in our study are also in accordance with the observations made by Wigand et al., ${ }^{13}$ Kopsa et al., ${ }^{14}$ Mitschke et al., ${ }^{15}$ and Johnson and Mathog. ${ }^{16}$ Hearing loss was found to be around $40 \%$ among CKD patients on hemodialysis in one study. ${ }^{2}$

Compared with healthy controls, a highly significant delay was observed in CKD patients in both absolute and interpeak BAER latencies in the present study. This is in agreement with Rossini et al., who reported prolongation of all ABR waves following wave I. ${ }^{19}$ Pagani et al. also noted the prolongation of $\mathrm{ABR}$ wave III and $\mathrm{V}$ latencies among patients with ESRD. ${ }^{17}$ According to Gafter et al., patients with ESRD had prolonged wave III and V latency and I-V interpeak latency prior to and following hemodialysis. ${ }^{18}$

The present study showed correlation of the absolute latencies of peaks I and III, and of interpeak latencies III to V and I to $\mathrm{V}$ with blood urea levels. However only the absolute latency of peak III, and interpeak latency III to V were found correlated with serum creatinine values. Blood urea nitrogen was the unique chemical index to correlate with BERA parameters in the study by Rossini et al. ${ }^{19}$ These findings are in contrast with various other studies which found no correlations between biochemical measures and changes in ABR absolute and interpeak latencies. ${ }^{18,20-22}$ There was no correlation of absolute or interpeak latencies with serum calcium or albumin levels in the present study. However Antonelli et al. reported that ABR wave latency was correlated to albumin and calcium levels. ${ }^{23}$ In addition, Pratt et al. reported changes in absolute and interpeak latency that were correlated to calcium ion changes prior to and following hemodialysis. ${ }^{24}$

The present study did not show improvement of BAER absolute wave latencies of the dialysed group compared to the non-dialysed group. The latencies for waves I and III were even worse in the dialysed group. There was a poor correlation of serum creatinine and BAER latencies in the present study. Serum urea and creatinine are nonspecific indicators of renal failure and may have a weak relationship to the pathophysiological processes which result in CNS dysfunction in uremia. It is possible that middle molecules or other uremic toxins may correlate better with uremic neurotoxicity. Non-dialysed patients have a higher residual GFR which may result in better clearance of middle molecules than patients on hemodialysis with a lower residual GFR, since it is believed that hemodialysis does not result in efficient removal of these middle molecules. This results in shorter delay in neural conduction in non-dialysed patients.

The limitation encountered in the present study is the absence of any intervention to treat the hearing dysfunction encountered on either PTA or BAER in these patients of CKD.

\section{Conclusions:}

The present study provides a concrete evidence to the otherwise disputed relation of auditory function in CKD proving that hearing is permanently affected by ESRD at all levels of the auditory neural pathway. BAER can prove useful in the early detection of hearing impairment in patients of CKD, even in the subclinical stage. However, further studies are required to devise specific therapies to halt as well as reverse this auditory dysfunction.

Conflict of interest: None. 


\section{References:}

1. Alport AC. Hereditary familial congenital haemorrhagic nephritis. Br Med J. 1927;1:504-6.

2. Bergstrom L, Jenkins P, Sando I, English GM. Hearing Loss in Renal Disease: Clinical and Pathologic studies. Ann Otol. $1973 ; 82: 555-76$

3. Turner Jr JS. Hereditary hearing loss with nephropathy. Acta Oto-Laryngologica. Supplementum. 1970;271:1.

4. Oda M, Preciado MC, Quick CA, Paparella MM. Labyrinthine pathology of chronic renal failure patients treated with hemodialysis and kidney transplantation. Laryngoscope. 1974;84(9):1489-506.

5. Beitz E, Zenner H-P, Schultz JE. Aquaporin Mediated Fluid Regulation in the Inner Ear. Cell Mol Neurobiol. 2003;23:31529.

6. Akiyama K, Miyashita T, Matsubara A, Mori N. The detailed localization pattern of $\mathrm{Na}+/ \mathrm{K}+/ 2 \mathrm{Cl}$ cotransporter type 2 and its related ion transport system in the rat endolymphatic sac. J Histochem Cytochem. 2010;58:759-63.

7. National Kidney Foundation (NKF-K/DOQI) clinical practice guidelines for CKD: evaluation, classification and stratification. Am J Kidney Dis. 2002;39:S1-266.

8. Zeigelboim BS, Mangabeira-Albernaz PL, Fukuda Y. High frequency audiometry and chronic renal failure. Acta Otolaryngol. 2001;121:245-8.

9. Vilayur E, Gopinath B, Harris DC, Burlutsky G, McMahon CM, Mitchell P. The Association Between Reduced GFR and Hearing Loss: A Cross-sectional Population-Based Study. Am J Kidney Dis. 2010;56:661-9.

10. Quick CA, Fish A, Brown C. The relationship between cochlea and kidney. Laryngoscope. 1973;83:1469-82.

11. Thodi C, Thodis E, Danielides V, Pasadakis P, Vargemezis V. Hearing in renal failure. Nephron Dial Transplant. 2006;21:3023-30.

12. Bains KS, Chopra H, Sandhu JS, Aulakh BS. Cochlear function in chronic kidney disease and renal transplantation: A longitudinal study. Transplant Proceed. 2007;39:1465-8.

13. Wigand ME, Meents O, Henneman H. Kochleo-Vestibulare Storungen bei Uramie in Beziehung zum Electrolytsoffwechsel und Glomerulumfiltrat. Schweiz Med Wsch. 1972;102:477-82.
14. Kopsa H, Kotzaurek R, Mitschke H, Schmidt P. Hearing disorders in chronic kidney failure. Monatsschr Ohrenheilkd Laryngorhinol. 1972;106(7):332-9.

15, Mitschke H, Schmit P, Zazgornik J, Kopsa H, Pils P. Effect of renal transplantation on uremic deafness: A long-term study. Audiology. 1977;16:530-4.

16. Johnson DW, Wathen RL, Mathog RH. Effects of hemodialysis on hearing threshold. Ann Otol Rhinol Laryngol. 1976;38:129-39.

17. Pagani C, Bazzi C, Arrigo G, Venturini CT, D’Amico G. Evoked potentials (VEPs and BAEPs) in a large cohort of short- and long-term haemodialysed patients. Nephrol Dial Transplant. 1993;8(10):1124-30.

18. Gafter U, Shvili Y, Levi J, Talmi Y, Zohar Y. Brainstem auditory evoked responses in chronic renal failure and the effect of hemodialysis. Nephron. 1989;53:2-5.

19 Rosini PM, Di-Stefano E, Febbo A, Di-Paolo B, Basciani M. Brain-stem auditory evoked responses (BAERs) in patients with chronic failure. Electroenceph Clin Neurophysiol. 1984;57:507-14.

20. Aspris AK, Thodi CD, Balatsouras DG, Thodis ED, Vargemezis V, Danielides V. Auditory brainstem responses in patients under treatment of hemodialysis. Renal Failure. 2008;30:383-90.

21. Baldini S, Radicioni R, Melappioni M, Baldassari M, Panichi $\mathrm{N}$, Pelliccioni G et al. Utility of electrophysiologic study using the blink reflex and brainstem evoked potentials for the evaluation of the course of uremic polyneuropathy. Minerva Urol Nephrol. 1995;47(1):13-17.

22. Niedzielska G, Katska E, Sikora P, Szajner-Milart I. ABR differences before and after dialysis. Int J Pediatric Otorhinolaryngology. 1999;48:27-9.

23. Antonelli A, Banfioli F, Garrubba V, Ghisellini M, Lamoretti $\mathrm{M}$, Nicolai $\mathrm{P}$ et al. Audiological findings in elderly patients with chronic renal failure. Acta Otolaryngologica. 1991;476:54-68.

24. Pratt H, Brodsky G, Goldsher M, Ben-David Y, Harari R, Podoshin L et al. Auditory brain-stem evoked potentials in patients undergoing dialysis. Electroencephalogr Clin Neurophysiol. 1986;63(1):18-24. 